\title{
Trace-nutrient-binding proteins in milk and the growth of bacteria in the gut of infant rabbits
}

\author{
BY C. B. COLE, K. J. SCOTT, M. J. HENSCHEL, M. E. COATES, \\ J. E. FORD AND R. FULLER \\ National Institute for Research in Dairying, Shinfield, Reading RG2 9AT
}

(Received 7 June 1982 - Accepted 20 September 1982)

\begin{abstract}
1. The influence of trace-nutrient-binding proteins on the growth of coliforms, streptococci and lactobacilli in the gastrointestinal tract was examined in neonatal rabbits delivered germ-free and dosed with an artificial flora (ESL), or born conventionally and dosed with ESL or rabbit faeces.

2. In the stomach and small intestine of both gnotobiotic and conventional animals the counts of coliforms were usually atypically high and those of streptococci were always low. In the colon the counts of coliforms and streptococci were high. Lactobacilli usually became established in the gut of the gnotobiotic animals but were not found in the conventional rabbits.

3. Sterilization (freeze-drying followed by $\gamma$-irradiation) of the milk decreased its capacity to bind added iron by $45 \%$ and vitamin $B_{12}$ by $30 \%$. When compared with raw milk, feeding of radiation-sterilized milk did not affect the viable count of coliforms and streptococci in the gut of gnotobiotic animals.

4. Saturating the nutrient-binding proteins in milk with Fe, folic acid and vitamin $B_{12}$ had no effect on the numbers of coliforms, streptococci and lactobacilli recovered from the intestine.
\end{abstract}

Vitamin $\mathrm{B}_{12}$, folate and iron in milk are strongly and specifically bound to minor whey proteins, which are generally present in excess. The unsaturated binding capacity varies widely between milks of different mammalian species. Thus, human milk binds approximately $80 \mathrm{ng}$ added cyanocobalamin/ml (Gregory \& Holdsworth, 1955) which is much more than its natural content of $0.3 \mathrm{ng}$ vitamin $\mathrm{B}_{12} / \mathrm{ml}$. Rabbits' milk is comparatively far richer in vitamin $\mathrm{B}_{12}$ (approximately $80 \mathrm{ng} / \mathrm{ml}$ ) and in unsaturated binder (equivalent to approximately $361 \mathrm{ng}$ cyanocobalamin $/ \mathrm{ml}$ ). With $\mathrm{Fe}$, human milk contains approximately $1.5 \mu \mathrm{g} / \mathrm{ml}$ (Blanc, 1964) and enough unsaturated lactoferrin to bind a further $3 \mu \mathrm{g} / \mathrm{ml}$; rabbits' milk contains approximately $4 \mu \mathrm{g} \mathrm{Fe} / \mathrm{ml}$ (Jordan et al. 1967) and unsaturated transferrin equivalent to approximately $20 \mu \mathrm{g} \mathrm{Fe} / \mathrm{ml}$. Human milk contains approximately $60 \mathrm{ng}$ folic acid $/ \mathrm{ml}$ and can bind a further $60 \mathrm{ng} / \mathrm{ml}$ (Ford et al. 1975). Rabbits' milk contains $200-600 \mathrm{ng}$ folic acid $/ \mathrm{ml}$ and has the capacity to bind a further $150 \mathrm{ng} / \mathrm{ml}$. The presence of these trace-nutrient binders has prompted much speculation concerning their physiological role, and their possible influence on the ecology of the intestinal microflora of the young mammal during the period from birth to weaning (Gullberg, 1973; Ford, 1974).

Lactoferrin (LF) and its serum counterpart transferrin exert a bacteriostatic or bactericidal effect against several bacteria, fungi and protozoa. There is evidence that they may be important host-protective components of human milk, and act to moderate the growth of Escherichia coli and other potential pathogens in the intestine (Brock, 1980). This activity has perhaps been most convincingly demonstrated in vitro and explained in simple terms of competition for Fe between micro-organisms and the Fe-binding protein. In vivo, LF may act in concert with specific antibody to check the growth of $E$. coli in the intestine (Bullen et al. 1972).

Just as LF may deprive Fe-dependent bacteria of an essential nutrient, so also may the vitamin $\mathrm{B}_{12}$ - and folate-binding proteins prevent uptake of these vitamins by bacteria. If it were true in vivo then, by protecting the dietary vitamin $B_{12}$ and folate, and perhaps also by intervening in the exchange of nutrients between vitamin producers and vitamin requirers 
in the microflora, the milk vitamin-binders would discourage the growth of vitamin $\mathrm{B}_{12}$ and folate-dependent species and benefit the vitamin economy of the host animal.

The rabbit's comparatively high content of trace-nutrient binders in the milk makes it a suitable model with which to test the hypothesis (Bullen et al. 1972; Gullberg, 1973; Ford, 1974) that the unsaturated binders might strongly influence the composition of the intestinal microflora. Gouet \& Fonty $(1973,1979)$ found that the flora in suckling rabbits, and of rabbits being hand-reared on rabbits' milk, was dominated by strict anaerobes, mainly Bacteroides sp. Streptococci appeared briefly, and reached maximum counts at $7-14 \mathrm{~d}$ after birth $\left(10^{7}-10^{9} / \mathrm{g}\right.$ contents); thereafter their numbers decreased progressively, and disappeared from the small intestine after weaning. Enterobacteria were generally absent in the early days of life; they appeared later, and their numbers in the small intestine peaked at $21 \mathrm{~d}$ after birth $\left(10^{7} / \mathrm{g}\right.$ contents $)$ and thereafter declined rapidly. Micrococci were found only rarely, and lactobacilli not at all.

In contrast with this finding that non-spore-forming, strictly anaerobic bacteria and facultatively anaerobic streptococci were established very early throughout the intestine, Smith (1965) reported unequivocally that the stomach and small intestine of suckling rabbits were virtually sterile, a phenomenon that was later attributed to the bactericidal effect of free fatty acids, predominantly $n$-octanoic and $n$-decanoic, liberated from the milk fat by lipolytic enzymes in the stomach (Cañas-Rodriguez \& Smith, 1966). Certainly it seems that the development of the intestinal microflora in the suckling rabbit is strongly influenced by the composition of the milk. Fonty et al. (1979) compared the composition and development of the microflora in rabbits which had been hand-reared from birth to $14 \mathrm{~d}$ on rabbits' milk with those in rabbits reared on a radiation-sterilized modified cows'-milk formula. In animals given rabbits' milk, the composition of the microflora was broadly similar to that earlier reported for suckling rabbits (Gouet \& Fonty, 1979), but with modified cows' milk the baby rabbits failed to thrive, and none survived after day 14 . Streptococci and enterobacteria quickly became established in the stomach and throughout the small intestine, giving counts of $10^{7}-10^{9} / \mathrm{g}$ at all levels. The authors concluded that it is impossible to obtain a digestive microflora in gnotobiotic animals similar to that of conventional rabbits, if they are not given does' milk. Even then, artificial rearing alters the microflora.

In experiments now reported our aim was to establish whether the trace-nutrient binders in rabbits' milk influence the composition of the intestinal flora in conventional rābbits and whether, in germ-free rabbits, the presence or absence of these binders in the milk might affect the ability of a 'model' microflora, requiring these nutrients, to colonize the gut.

\section{METHODS}

Test organisms

The bacteria used in this study were Lactobacillus leichmannii NCDO 301, Lactobacillus case NCDO 243, Streptococcus faecium NCDO 1258 and three strains isolated from the pig gut (Lactobacillus sp. SP3/1, S. faecium 353 and E. coli 272). The latter three strains were chosen for their dependence on vitamin $B_{12}$, folic acid and $\mathrm{Fe}$ respectively and would, therefore, be expected to be susceptible to the antibacterial effects of the corresponding nutrient binders.

When required for the in vivo experiments lactobacilli were grown in MRS broth (de Man et al. 1960), streptococci in yeastrel-glucose broth (YGB) and E. coli in glucose-lemco broth.

\section{Measurement of vitamin-binding capacities}

The capacity of the various test milk preparations to bind added vitamins was measured by addition of excess $\left[\mathrm{G}^{-}{ }^{3} \mathrm{H}\right]$ cyanocobalamin, or $\left[\mathrm{G}^{-}{ }^{3} \mathrm{H}\right]$ folic acid, to a sample of milk. Dialysis took place for $48 \mathrm{~h}$ at $4^{\circ}$ against eight successive $100 \mathrm{ml}$ portions of buffer solution, 
pH 7.2 , containing $0.15 \mathrm{M}$-sodium chloride and $0.02 \mathrm{M}$-sodium phosphate (for folic acid measurements the buffer also contained $2 \mathrm{~g}$ ascorbic acid/1). The residual activity was measured by use of a liquid scintillation analyser.

\section{Measurement of Fe-binding capacities}

Defatted milk serum was dialysed for $48 \mathrm{~h}$ at $4^{\circ}$ against $0.05 \mathrm{M}$-phosphate buffer, $\mathrm{pH} 7 \cdot 0$, containing $0.01 \mathrm{M}$-sodium bicarbonate, and the unsaturated Fe-binding capacity was measured by titration against a solution of $1.05 \mathrm{~mm}-\mathrm{Fe}$ (as ferric alum) in $>1 \mathrm{~mm}-$ nitrilotriacetic acid at $\mathrm{pH} 7.0$ (Bate et al. 1967).

\section{Microbiological assay of vitamin $B_{12}$ and folic acid contents}

Vitamin $B_{12}$ activity in milk was measured with Lactobacillus leichmannii NCDO 301 after digestion of the test sample with cyanide-activated papain (EC 3.4.22.2) as described by Gregory (1954).

Folate activity was measured with Lactobacillus casei NCDO 243 as described by Ford et al. (1972).

\section{In vitro inhibition of bacteria by the milks}

E. coli. The ability of milk to inhibit the growth of $E$. coli was tested by comparing the rate of growth of the test culture in millipore-filtered milk, dialysed as described previously with and without addition of Fe to saturate the milk transferrin.

Streptococci and lactobacilli. Diluted millipore-filtered milk was added to sterilized folate or vitamin $\mathbf{B}_{12}$ assay medium containing graded amounts of the vitamins. The growth responses were compared to those in similar cultures to which no milk had been added.

\section{Feeding experiments with young rabbits}

Animals. When required germ-free, the rabbits were delivered by hysterectomy just before term into stainless-steel isolators (Gustafsson, 1959). They were housed on muslin towels in wire-mesh cages and bottle-fed twice daily with the appropriate milk preparations. Conventional bottle-fed controls were removed from the doe soon after birth and housed in similar cages. The ambient temperature in both environments was maintained at approximately $35^{\circ}$. Naturally-reared controls were housed with and nursed by the doe.

\section{Diet and feeding}

Milk was collected under hygienic conditions from a number of does in their third week of lactation. Some was transferred to sterile glass bottles and stored at $-20^{\circ}$; when required for use, each bottle of milk was thawed, externally sterilized and aseptically entered into the isolator. Milk prepared in this way was referred to as 'raw'. Before feeding, a small sample was removed for bacterial counting; counts were low in all instances.

In Expt 1, some of the milk was sterilized by $\gamma$-irradiation. Because liquid milk deteriorates on irradiation (Ford et al, 1962) it was first freeze-dried and vacuum packed before exposure to $0.025 \mathrm{~Gy}$. It was reconstituted with sterile water inside the isolator.

Both diets were readily taken by the pups from small bottles fitted with latex teats.

In all experiments, the pups were killed at 7-8 $\mathrm{d}$ of age and the gut contents removed for bacteriological examination.

\section{Expt 1}

This was designed to show any difference between raw and sterilized milks on the establishment of a 'model' gut flora in the rabbit.

One litter of eight germ-free rabbits was divided into two groups of four. One group was 
bottle-fed on reconstituted, irradiated, freeze-dried milk, the other on raw milk. A third group of four rabbits from a second litter was housed with and nursed by the doe as controls.

At $3 \mathrm{~d}$ of age, all the neonates were given by mouth a suspension in saline of $E$. coli 272 , S. faecium 353 and a Lactobacillus SP3/1 (ESL).

\section{Expt 2}

One litter of six germ-free rabbits was divided into two groups of three. One group was given raw milk, the other raw milk to which $\mathrm{Fe}$ (as ferrous ammonium sulphate), folic acid and vitamin $\mathbf{B}_{12}$ had been added to saturate the binding capacities, in order to test the effect of saturation of the binding proteins on the establishment of an artificial flora.

At $3 \mathrm{~d}$ of age the animals were dosed with a suspension of the test cultures, ESL, as described previously.

\section{Expt 3}

From a conventional litter of nine rabbits, six were removed soon after birth and divided into two groups of three. One group was bottle-fed on raw milk, the other on raw milk with the binding capacities saturated as in Expt 2. The remaining three pups were left housed with and nursed by the doe.

At the age of $1 \mathrm{~d}$, all the neonates were dosed with a suspension of fresh faeces in milk from the doe in order to test the effect of the provision of Fe, folic acid and vitamin $B_{12}$ on a naturally occurring rabbit flora.

\section{Expt 4}

A single litter of five conventionally-born rabbits, housed with and nursed by the doe, was divided into two groups. One, containing two pups, was given a suspension of the doe's faeces at $1 \mathrm{~d}$ of age as described previously, the other group of three was left uninoculated in order to test the effect of inoculating faeces on the development of a neonatal rabbit gut flora.

\section{Viable counting of bacteria}

Samples of gut content from the stomach, small intestine and colon were suspended in YGB to give a concentration of $100 \mathrm{~g} / 1$. Further dilutions were made in quarter-strength Ringer's solution. The diluted samples were surface inoculated on to MacConkey's agar for the detection of coliforms, TITg agar (Barnes, 1956) for streptococci and acetate agar (Rogosa et al. 1951) for lactobacilli. MacConkey's agar and TITg were incubated aerobically at $37^{\circ}$ for 1 and $2 \mathrm{~d}$ respectively; acetate agar was incubated anaerobically at $37^{\circ}$ for $2 \mathrm{~d}$.

Similar methods were used for counting the faeces suspension used for dosing the baby rabbits. Lactobacilli were never detected, streptococci were always present but at counts of less than $10^{4}$ colony-forming units (cfu)/g and coliforms were detected at counts of $10^{2}-10^{6}$ $\mathrm{cfu} / \mathrm{g}$.

The viable counting techniques were chosen to estimate the numbers of the three test organisms in the gnotobiotes and their corresponding groups in the conventional animals. Consequently, no results are available for the numbers of strictly anaerobic bacteria.

\section{RESULTS}

Vitamin content and excess binding capacities

The folic acid content of the rabbit-milk samples varied between 246 and $538 \mathrm{ng}$ folic acid $/ \mathrm{ml}$ and they had unsaturated capacity to bind between 126 and $180 \mathrm{ng} / \mathrm{ml}$. Freeze-drying followed by irradiation caused a loss of approximately $10 \%$ in folate content, but no loss of excess binding capacity. 


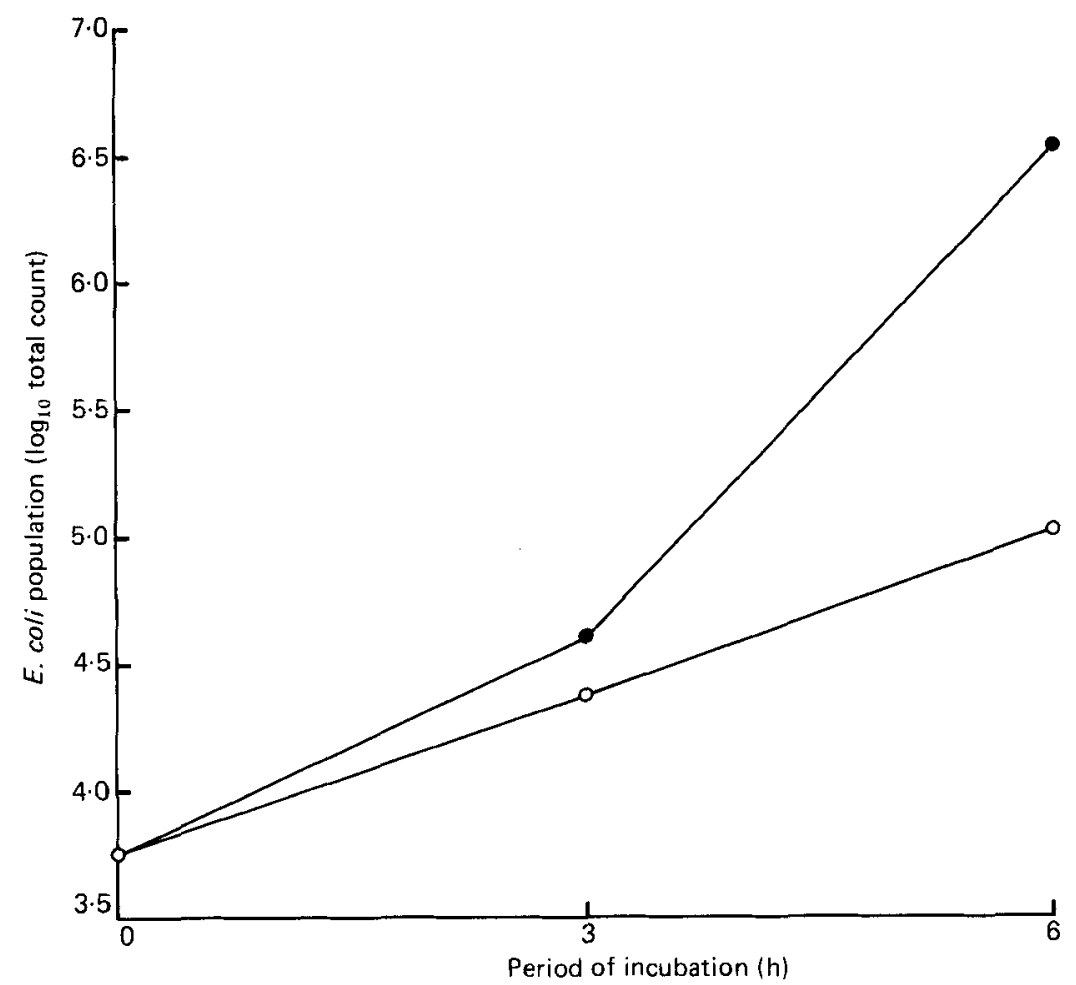

Fig. 1. Influence of rabbit milk, and the effect of adding iron, on the growth of Escherichia coli: $(\mathrm{O}-\mathrm{O})$ raw rabbit milk, (O-O) milk with added Fe to saturate the milk transferrin.

The vitamin $B_{12}$ content averaged $80 \mathrm{ng} / \mathrm{ml}$ and the unsaturated binding capacity $361 \mathrm{ng} / \mathrm{ml}$. Freeze-drying followed by irradiation caused a $30 \%$ loss in content of both vitamin $B_{12}$ and excess binding capacity.

\section{Excess Fe-binding capacity}

The rabbit milk bound approximately $20 \mu \mathrm{g} / \mathrm{ml}$ of added Fe. Freeze-drying followed by irradiation caused a loss of approximately $45 \%$ in this binding capacity.

\section{In vitro inhibition of growth of $\mathrm{E}$. coli 272}

Fig. 1 shows the influence of raw rabbit milk, with and without added $\mathrm{Fe}$, on the growth of $E$. coli 272 . In the absence of added $\mathrm{Fe}$, viable counts increased four times in $3 \mathrm{~h}$ and twenty-two times in $6 \mathrm{~h}$, compared with seven times and 1100 times in milk with added Fe. Similar results were obtained with reconstituted, irradiated freeze-dried milk.

\section{In vitro inhibition of growth of lactobacilli and streptococci}

Two strains of lactobacilli were tested: $L$. leichmannii NCDO 301, which requires vitamin $B_{12}$ absolutely and is widely used for the microbiological assay of the vitamin, and Lactobacillus sp. strain $3 / 1$ isolated from the pig intestine. Similarly, two strains of streptococci were tested: S. faecium NCDO 1258, which is one of the organisms used for the microbiological assay of folic acid, and strain 353 isolated from the pig intestine.

Figs. 2 and 3 show that the growth of both the assay organisms was inhibited by the milk 


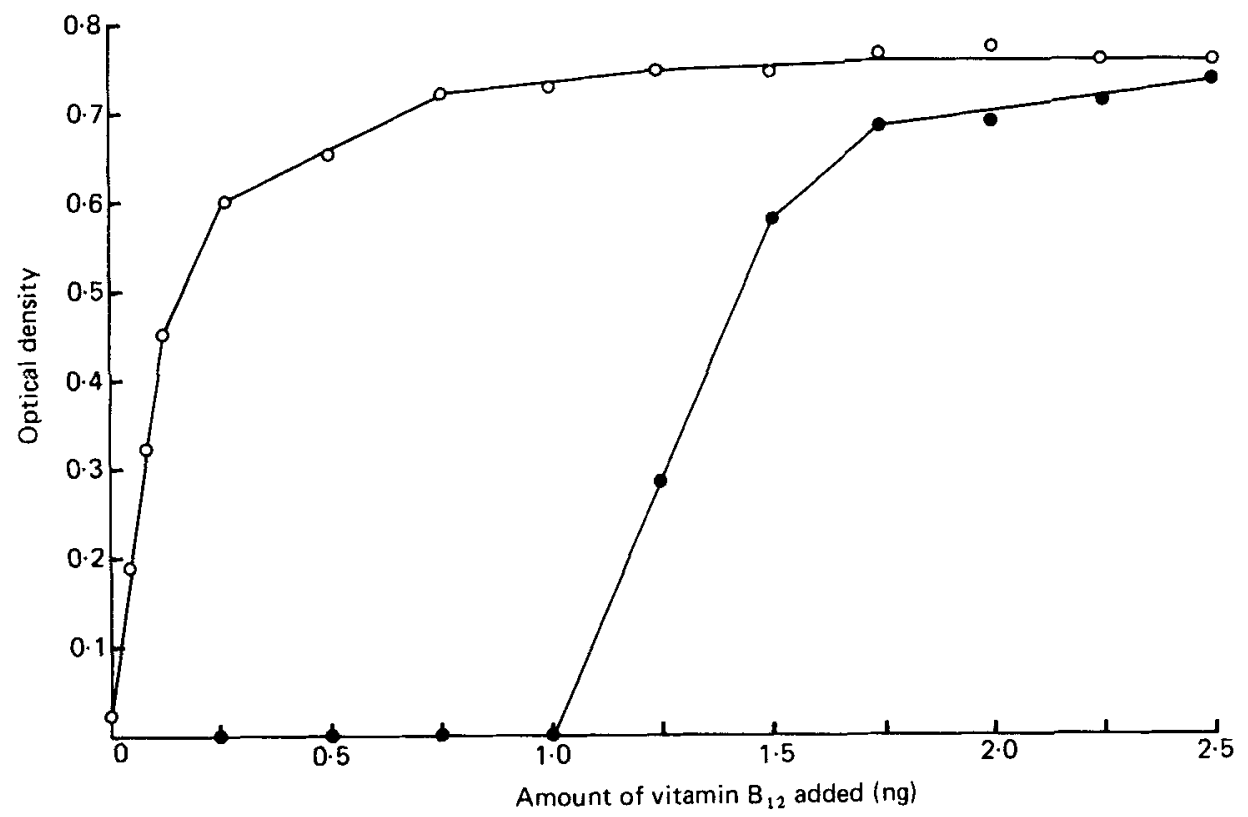

Fig. 2. Influence of rabbit milk on the growth response of Lactobacillus leichmannii to graded concentrations of vitamin $B_{12}:(O-O)$ vitamin $B_{12}$ alone, $(-\infty)$ with added freeze-dried, irradiated rabbit milk. Vitamin $B_{12}$ was added to $5 \mathrm{ml}$ portions of culture medium with and without diluted milk equivalent to $4 \mu \mathrm{l}$ of the original milk.

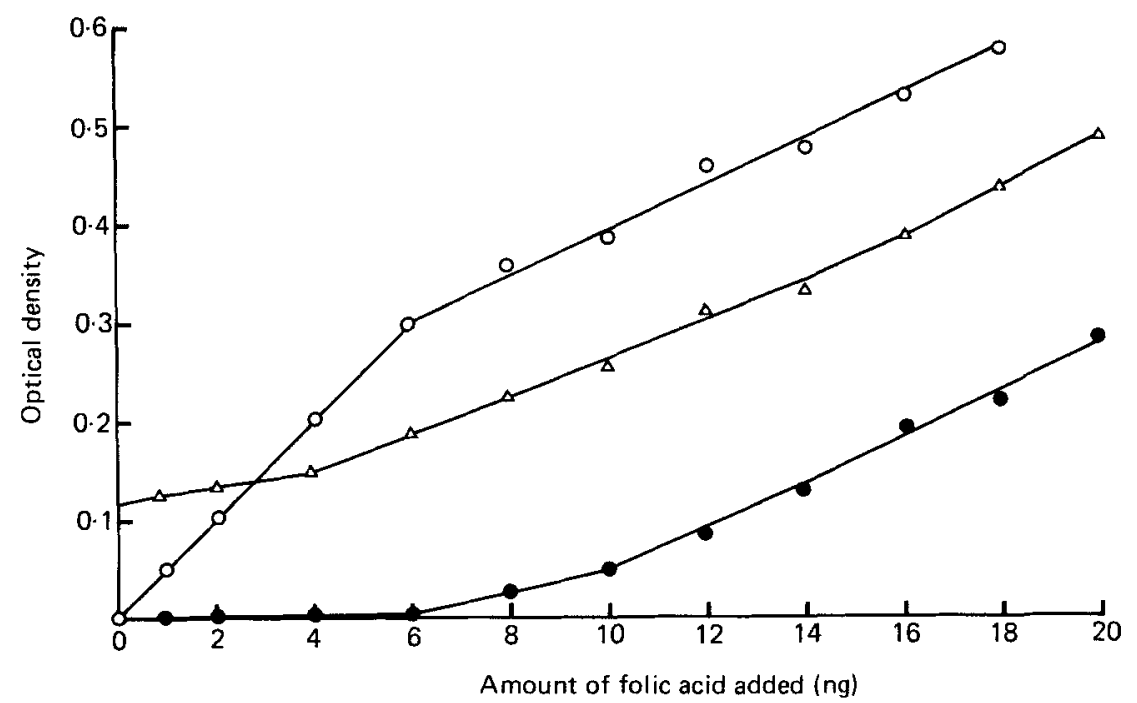

Fig. 3. Influence of rabbit milk on the growth response of Streptococcus faecium to graded concentrations of folic acid: $(\mathrm{O}-\mathrm{O})$ folic acid alone, $(--)$ with added raw rabbit milk, $(\Delta-\Delta)$ with added freeze-dried, irradiated rabbit milk. Folic acid was added to $3 \mathrm{ml}$ portions of culture medium with and without diluted milk, equivalent to $100 \mu$ lof the original milk. 
until the excess binding capacity had been saturated. However, in irradiated milk S. faecium was apparently capable of limited growth in the presence of unsaturated folate binder.

The pig isolates behaved differently in that they were able to grow in rabbits' milk on prolonged incubation, but optimal growth was not achieved until the excess binding capacity had been saturated.

Expt 1. The numbers of coliforms, streptococci and lactobacilli found in the intestine of gnotobiotic rabbits associated with the three test organisms and maintained for $8 \mathrm{~d}$ on the doe or bottle-fed for $7 \mathrm{~d}$ on raw or irradiated rabbits' milk are shown in Table 1 . The counts in suckling rabbits were low. In bottle-fed rabbits given raw milk the coliform count in the small intestine was higher but counts of streptococci and lactobacilli were low. By contrast, in bottle-fed rabbits given irradiated milk the count of coliforms was much higher, as was that of lactobacilli which were present thoughout the gut at counts of $10^{5}-10^{6} / \mathrm{g}$ contents. However, the counts of streptococci in the stomach and small intestine were low.

With all three organisms the numbers were greater in the colon than in the anterior gut and greater in bottle-fed than in suckling animals.

Expt 2. In an attempt to avoid the atypical flora associated with rabbits given irradiated milk in Expt 1, raw milk was used in this and all subsequent experiments. The rabbits in this experiment received either untreated raw milk or raw milk in which the nutrient binders had been saturated by excess $F e$, folic acid or vitamin $\mathbf{B}_{\mathbf{1 2}}$. Microbiological analysis after $8 \mathrm{~d}$ showed that saturation of the nutrient binder had not resulted in any increase in the counts of the bacteria. Coliforms were present at high counts throughout the gut, even without the addition of $\mathrm{Fe}$ to the milk. In no situation was the bacterial count increased in rabbits receiving the saturated milk.

Expt 3. In this experiment the rabbits were dosed by mouth with a suspension of rabbit faeces collected from healthy adult conventional rabbits to ensure early contact with typical rabbit-gut flora and assigned to the three groups shown in Table 1. Bacteriological counts were made at $8 \mathrm{~d}$ of age. All three groups gave similar counts which were much the same as those obtained in Expt 2, except that no lactobacilli were recorded from any of the samples.

Expt 4. In the final experiment, two of the five rabbits were dosed with a suspension of faeces to assess its effect on the composition of the gut microflora. All five animals were nursed by the doe until $7 \mathrm{~d}$ of age when the gut microflora was examined. The results were closely similar to those of Expt 3; coliforms were present in high numbers in all animals whether or not they had been dosed with faeces.

\section{DISCUSSION}

In Expt 1, when a comparison was made between the bottle-feeding of raw and irradiated freeze-dried milk, the lactobacillus established itself only in the gnotobiotic animals given the irradiated freeze-dried milk. E. coli established itself better in animals given irradiated freeze-dried milk than in those given raw milk. These organisms were virtually absent from the gut of suckling animals. This suggests a possible effect due to the feeding of the irradiated freeze-dried milk. However, in Expt 2 the coliforms and lactobacilli were also established in the gut of gnotobiotic animals given raw milk. It is difficult, therefore, to conclude that the effect in the gnotobiotic animals was entirely due to the irradiation treatment.

Irradiation certainly caused a reduction in the capacity of the milk to bind added Fe and vitamin $B_{12}$, as does heating (Ford et al. 1977). Beerens et al. (1980) have shown that a factor in human milk which stimulates the growth of Bifidobacterium longum was destroyed by freeze-drying and irradiation. It must, therefore, not be assumed that freeze-drying and irradiation sterilization of milk is a completely innocuous procedure.

It has been demonstrated in vitro that milk will inhibit the uptake by bacteria of added 


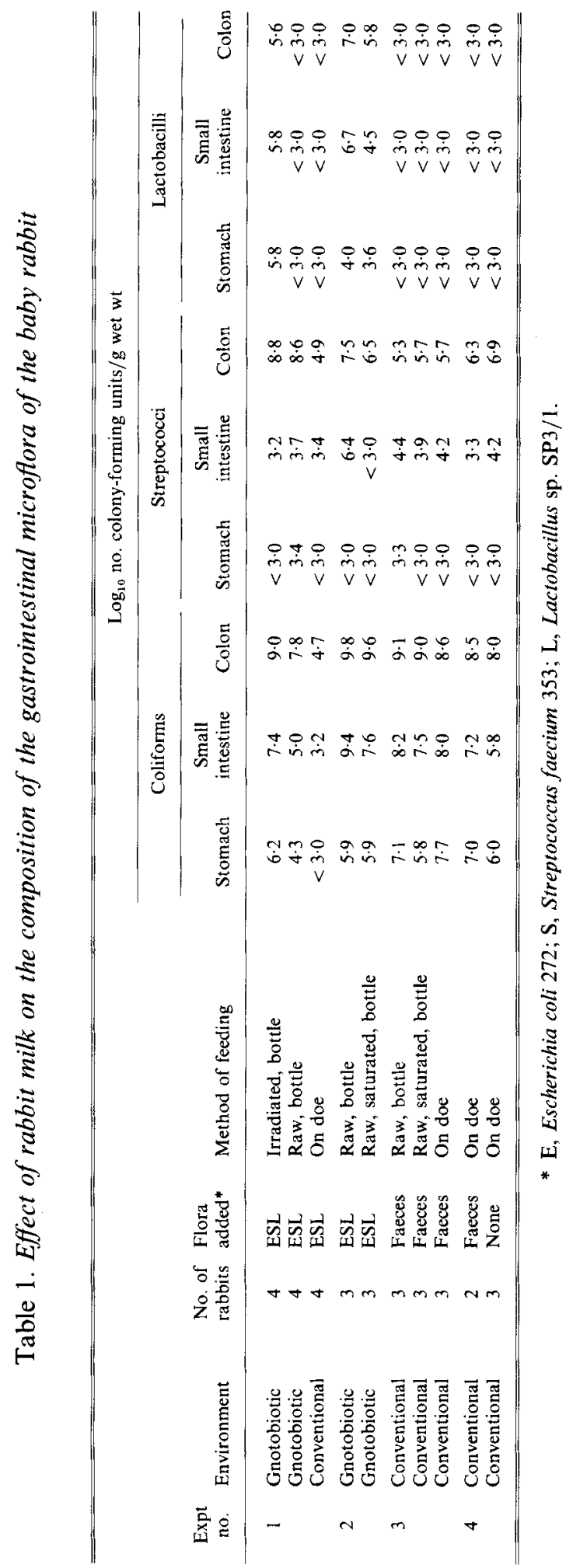


$\mathrm{Fe}$ or vitamin $\mathrm{B}_{12}$ and folate until the excess binding capacity has been saturated (Ford, 1974). More recently it has been shown that both milk and the isolated binding proteins will inhibit the growth of folic acid- and vitamin $\mathrm{B}_{12}$-requiring organisms $(\mathrm{K}$. J. Scott, unpublished results). However, in Expts 2 and 3, which were designed to demonstrate any effect of saturation of these binders on the growth of bacteria in vivo, coliforms grew well in the presence of unsaturated Fe binder, and the low levels of streptococci and lactobacilli were not increased by the addition of folic acid and vitamin $B_{12}$ to saturate the binding proteins.

Lactobacilli were not found in conventional animals irrespective of the treatment, but were present throughout the intestine, at counts of $10^{4}-10^{7} / \mathrm{g}$ contents, in all but one of the experiments with gnotobiotic animals. (Lactobacilli are not normally recovered from the gut of rabbits although Fesce et al. 1977 found counts of $10^{6} / \mathrm{g}$ in faeces.)

In the present study, high counts of streptococci were generally found only in the colon of conventional and gnotobiotic animals.

Counts of coliforms were variable. In Expt 1 the coliform count was lower in the conventional animals than in the gnotobiotic, suggesting that the large numbers of anaerobic bacteria present in the lower gut (Smith, 1965) were having an effect on the composition of the flora. However, in a subsequent experiment coliforms grew to high levels in conventional animals. The outcome may depend on the strain of $E$. coli or the type of anaerobe present in the gut or on the nature of the anaerobic flora. The does were all practising coprophagy and in the baby rabbits there was evidence of coprophagy, as judged by the presence of faecal pellets in the stomach contents of some individuals. However, the significance of this habit in relation to bacterial colonization of the gut is impossible to assess without data from animals in which coprophagy was prevented.

There was no evidence from the results of Expt 3 that suckling was superior to bottle-feeding in controlling the coliform population. The possibility that the high levels of coliforms were due to dosing with faeces was discounted because large numbers of coliforms were also recovered from rabbits that had been allowed to acquire a natural flora (Expt 4). These findings with coliforms were unexpected because in the past they have been usually recorded as absent, or present in very low numbers (Smith, 1965; Fuller \& Moore, 1971; Fesce et al. 1977; Gouet \& Fonty, 1979; von Malthes, 1981).

In vitro investigations of the bacteriostatic properties of milk have shown that, even with a relatively high level of inoculation, growth may be delayed for as long as $6 \mathrm{~h}$. Factors such as residence time in the stomach, the role of bicarbonate in potentiating the antibacterial effect of transferrin (Reiter et al. 1975) and the relative resistance of different strains of $E$. coli to bactericidal fatty acids (Smith, 1966) may be important in the establishment of $E$. coli in the stomach. It has been reported (Samson et al. 1980) that in vitro digestion of human milk with trypsin abolished its bacteriostatic effect on a vitamin $\mathrm{B}_{12}$-dependent organism, and this finding seems to argue against an in vivo bacteriostatic role for the vitamin $B_{12}$ binding protein in milk. However, Ford et al. (1975) found that chyme in the stomach and small intestine of piglets given sows' milk contained unsaturated vitamin $B_{12}$ binding protein, partly endogenous and partly derived from the milk, which prevented uptake of $\left[\mathrm{G}^{3}-\mathrm{H}\right]$ cyanocobalamin by the intestinal bacteria.

Our findings provide no evidence that the various trace-nutrient-binding proteins present in rabbits' milk influence the composition of the gut flora. This conclusion is based on the behaviour of coliforms, streptococci and lactobacilli after saturation of the nutrient binders in milk. Although strictly anaerobic bacteria are dominant in the gut of conventional rabbits, the three facultatively anaerobic strains used in gnotobiotic experiments were selected because of their dependence on the three nutrients being studied. The counts of these three indicator organisms were unchanged and it seems likely that, if the dominant 
anaerobic flora in the lower gut of conventional rabbits contains strains which require the test nutrients, they would also be unaffected.

Although the counts of coliforms were usually atypically high, the counts of streptococci and lactobacilli in the stomach were consistently low and were not increased in the absence of unsaturated milk binder. It may well be that for these two groups of bacteria, the bactericidal system based on fatty acids (Smith, 1965) was operating.

The final composition of the gut flora may be determined by the activity and interaction of several components in the milk. However the significance of the nutrient-binding proteins in relation to gut ecology remains uncertain.

The authors would like to thank Mr J. P. Fordham for care of the gnotobiotic rabbits and $\mathrm{Mr} \mathrm{P}$. H. Anderson for technical assistance.

\section{REFERENCES}

Barnes, E. M. (1956). J. appl. Bact. 19, 193.

Bate, G. W., Billups, C. \& Saltman, P. (1967). J. biol. Chem. 242, 2810.

Beerens, E. M., Romond, C. \& Neut, C. (1980). Am. J. clin. Nutr. 33, 2434.

Blanc, B. (1964). Les protéins du lactosérum. Leurs relations avec l'immunité et le métabolism due fer. Thèse, Medecine et Hygiène, Université de Genève.

Brock, J. H. (1980). Archs Dis. Childh. 55, 417.

Bullen, J. J., Rodgers, H. J. \& Leigh, L. (1972). Br. med. J. i, 69.

Cañas-Rodriguez, A. \& Smith, H. W. (1966). Biochem. J. 100, 79.

de Man, J. C., Rogosa, M. \& Sharpe, M. E. (1960). J. appl. Bact. 23, 130.

Fesce, A., Ceccarelli, A., Fesce, E. \& Balsari, A. (1977). Folia. Vet. Lat. 7, 225.

Fonty, G., Gouet, Ph. \& Riou, Y. (1979). Annls Biol. anim. Bioch. Biophys. 19, 567.

Ford, J. E. (1974). Br. J. Nutr. 31, 243.

Ford, J. E., Gregory, M. E. \& Thompson, S. Y. (1962). Int. Dairy Congr. XVI, Copenhagen, A, 917.

Ford, J. E., Knaggs, G. S., Salter, D. N. \& Scott, K. J. (1972). Br. J. Nutr. 27, 571.

Ford, J. E., Law, B. A., Marshall, V. M. E. \& Reiter, B. (1977). J. Pediat. 90, 29.

Ford, J. E., Scott, K. J., Sansom, B. F. \& Taylor, P. T. (1975). Br. J. Nutr. 34, 469.

Fuller, R. \& Moore, J. H. (1971). Lab. Anim. 5, 25.

Gouet, Ph. \& Fonty, G. (1973). Annls Biol. anim. Bioch. Biophys. 13, 733.

Gouet, Ph. \& Fonty, G. (1979). Annls Biol. anim. Bioch. Biophys. 19, 553.

Gregory, M. E. (1954). Br. J. Nutr. 8, 340.

Gregory, M. E. \& Holdsworth, E. S. (1955). Biochem. J. 59, 329.

Gullberg, R. (1973). Scand. J. Gastroent. 8, 497.

Gustafsson, B. E. (1959). Ann. N.Y. Acad. Sci. 78, 17.

Jordan, S. M., Kaldor, I. \& Morgan, E. H. (1967). Nature, Lond. 215, 76.

Reiter, B., Brock, J. H. \& Steel, E. D. (1975). Immunology $28,83$.

Rogosa, M., Mitchell, J. A. \& Wiseman, R. F. (1951). J. Bact. 62, 132.

Samson, R. R., Mirtle, C. \& McCelland, D. B. L. (1980). Acta. Paed. scand. 59, 517.

Smith, H. W. (1965). J. Path. Bact. 90, 495.

Smith, H. W. (1966). J. Path. Bact. 91, 1.

von Malthes, S. (1981). Kleintier. Prax. 26, 383. 